\title{
Pattern of Response to Divalproex, Lithium, or Placebo in Four Naturalistic Subtypes of Mania
}

\author{
Alan C. Swann, M.D., Charles L. Bowden, M.D., Joseph R. Calabrese, M.D., \\ Steven C. Dilsaver, M.D., and David D. Morris, Ph.D.
}

We investigated effects of antimanic treatments on specific aspects of mania, prediction of response, and the existence of naturalistic subgroups of patients with different treatment response in 179 inpatients randomized to antimanic treatment with lithium, divalproex, or placebo. Psychiatric symptom ratings were conducted by clinicians and nurses before and during treatment. Factor analysis using physician and nurse rating scales, followed by a cluster analysis, yielded anxious-depressive, psychotic, classic, and irritable subtypes. We compared: (1) treatment effects on factor scores; (2) responses to treatment across subtypes; and (3) pattern of symptom change with each treatment.
The anxious-depressed subtype did not respond to any treatment; the psychotic and classic subtypes responded similarly to lithium and to divalproex; and the irritabledysphoric subtype responded better to divalproex than to lithium. Overall, divalproex improved impulsivity and hostility significantly more than placebo, and lithium or divalproex improved hyperactivity more than placebo. These data suggest that there are naturalistic subtypes of manic episodes with different responses to treatment.

[Neuropsychopharmacology 26:530-536, 2002]

(C) 2002 American College of Neuropsychopharmacology.

Published by Elsevier Science Inc.
KEY WORDS: Bipolar disorder; Mania; Factor analysis; Cluster analysis; Mixed state; Lithium; Valproate; Placebo; Randomized clinical trial

Treatments for mania vary in their apparent mechanisms of action and predictors of response. Specific symptom changes may result from direct effects on underlying neuronal systems. Although manic states have high specificity, as evidenced by the fact that manic episode has the highest interrater reliability of any Axis I diagnosis (First et al. 1996), mania is not a unitary state. Symptomatic dimensions vary in ways known to be as-

From the University of Texas-Houston Health Science Center and Harris County Psychiatric Center, Houston, Texas (ACS), University of Texas Health Science Center, San Antonio, TX (CLB), Case-Western Reserve University School of Medicine (JRC), Sandusky, Ohio (SCD), and Abbott Laboratories, North Chicago, Illinois (DDM).

Address correspondence to: Dr. A.C. Swann, UT-Houston Medical School, P.O. Box 20708, Houston TX 77225, Tel.: (713) 500-2555, Fax: (713) 500-2557.

Received February 12, 2001; revised August 27, 2001; accepted October 8, 2001.

Online publication: 10/9/01 at www.acnp.org/citations/Npp 1009801184 sociated with response. Psychotic mania appears relatively unresponsive to lithium (Tohen et al. 1990). Mania with depressive features is more responsive to divalproex than to lithium (Swann et al. 1997). A high state of arousal, possibly manifested neurochemically by increased catecholaminergic and hypothalamic-pituitary-adrenocortical function (Swann et al. 1992) and behaviorally by irritability, depression, or anger (Swann et al. 1986), may reduce the effectiveness of lithium in manic episodes. Identification of fundamental behavioral subtypes that differentially predict response to specific treatments could guide treatment choice.

Symptom changes during treatment could result from direct effects of the treatment drug on behavior, or could be epiphenomena of effects on neuronal systems that underlie manic episodes. In the former case, treatments might produce distinctive patterns of change, while if the latter were the case, symptom change in responders would be similar regardless of treatment.

We compared response to lithium, divalproex, and placebo in patients hospitalized for manic episodes (Bowden et al. 1994). Response to divalproex was better 
in patients whose manic episodes had depressive features (Swann et al. 1997), or many lifetime episodes of illness (Swann et al. 1999), but overall response to lithium and divalproex was similar and better than that to placebo (Bowden et al. 1994). Cluster analysis based on factors extracted from principal components analysis of pretreatment symptom ratings revealed four distinct subtypes: anxious/depressed, psychotic, classic, and irritable, all with similarly severe core manic syndromes (Swann et al. 2001). Here, we report: (1) distribution of six behavioral factors across the four episode subtypes; (2) treatment effects on the factors; (3) treatment response for the four subtypes; and (4) factor scores in subjects who responded to the three treatments. Our hypotheses were that: (1) lithium would be more effective against hyperactivity, while divalproex would be more effective against dysphoria and hostility; (2) lithium would be more effective than divalproex in euphoric mania, but less effective in other presentations; and (3) treatment responders would have similar patterns of factor score changes, regardless of treatment.

\section{METHODS}

After complete explanation of the study and written informed consent, 179 subjects entered a three-week, double-blind, parallel groups comparison of lithium, divalproex or placebo for inpatient treatment of primary acute manic episodes. Of these, 164 subjects had behavioral data complete enough for the factor and cluster analyses. Numbers of subjects in different analyses vary slightly because of missing rating scale or item data for both baseline and post-treatment data, and variable rates of completion of treatment among the groups. The study has been described in detail (Bowden et al. 1994). Subjects met Research Diagnostic Criteria (Spitzer et al. 1978) for manic episodes, based on structured interview using the Schedule for Affective Disorders and Schizophrenia (Spitzer and Endicott 1978a). After the longer of three days, or five half-lives of any psychotropic medicine being taken at study entry, subjects were randomized to one of the three treatments, in a placebo-divalproex-lithium ratio of 2:2:1. Clinical ratings consisting of the Change version of the SADS (Spitzer and Endicott 1978b) and the Affective Disorder Rating Scale (ADRS) (Murphy et al. 1982) were administered the day before randomization and weekly during treatment.

Group comparisons used 1- or 2-way analysis of variance, as specified in the text, with post-hoc comparisons using the Newman-Keuls test if the appropriate analysis of variance or interaction was significant. If requirements for analysis of variance were not met (normal distribution and homogeneity of variance), natural log transformation was used. Change scores were the difference between baseline and final treatment scores. Correlation analysis used Spearman or Pearson $r$ depending on distribution of data. Statistical tests were 2-tailed, except for comparisons to zero or placebo in Table 4, which were 1-tailed since we did not consider significance of changes worse than zero or worse than placebo (Winer 1971).

Standardized factor scores from principal components analysis (Swann et al. 2001) were converted to rating scale-related scores by adding the ratings with loadings of at least 0.5 and dividing by the number of such ratings for each factor. This was done to make the factor

Table 1. Rating Scale Composition of Factors

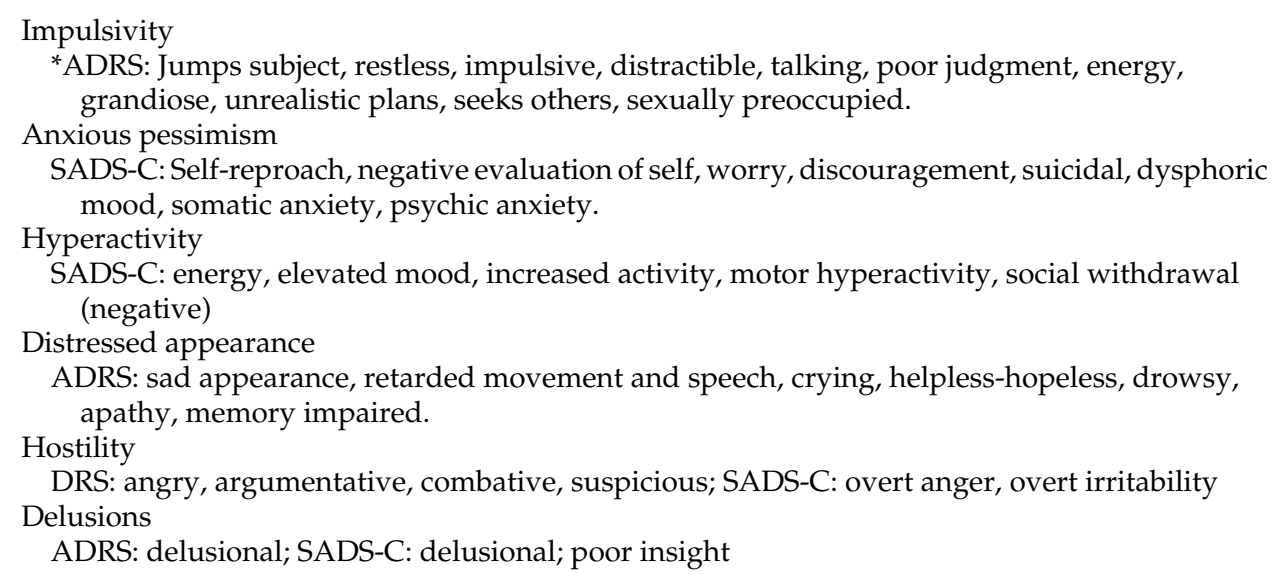

Based on items with loadings greater than 0.5 (Swann et al. 1999). ADRS = Affective Disorder Rating Scale (Murphy et al. 1982); SADS-C = Change version of Schedule for Affective Disorders and Schizophrenia (Spitzer and Endicott 1978b).

${ }^{*}$ Each of these nurse-rated items is scored on the basis of observed behavior, based on instructions such as "the patient is observed to jump from one subject to another while speaking" 
Table 2. Subscale Rating Scores for Mania Subtypes

\begin{tabular}{|c|c|c|c|c|c|}
\hline & \multicolumn{5}{|c|}{ Subtypes } \\
\hline & Depressive & Psychotic & Classic & Irritable & $\mathbf{F}(\mathbf{P})$ \\
\hline Factors & 22 & 42 & 72 & 29 & $(3,161)$ \\
\hline Impulsivity & $3.67 \pm 1.03$ & $3.86 \pm 0.96$ & $3.24 \pm 1.08$ & $3.45 \pm 1.13$ & $3.6(.014)$ \\
\hline Anxious Pessimisma & $3.12 \pm 0.57$ & $1.28 \pm 0.45$ & $1.70 \pm 0.56$ & $1.76 \pm 0.55$ & $59\left(10^{-7}\right)$ \\
\hline Hyperactivity $^{\mathrm{b}}$ & $2.67 \pm 0.73$ & $2.90 \pm 0.97$ & $2.83 \pm 0.67$ & $1.75 \pm 0.94$ & $14.3\left(10^{-6}\right)$ \\
\hline Distressed Appearance ${ }^{c}$ & $2.06 \pm 0.70$ & $1.53 \pm 0.54$ & $1.43 \pm 0.44$ & $2.48 \pm 1.05$ & $21.4\left(10^{-6}\right)$ \\
\hline Hostility $^{\mathrm{d}}$ & $2.77 \pm 1.25$ & $2.68 \pm 1.07$ & $2.16 \pm 0.87$ & $3.39 \pm 1.03$ & $10.9\left(2 \times 10^{-6}\right)$ \\
\hline Delusions $^{\mathrm{e}}$ & $2.94 \pm 1.27$ & $4.48 \pm 0.72$ & $1.90 \pm 0.69$ & $3.39 \pm 1.15$ & $77.4\left(10^{-7}\right)$ \\
\hline
\end{tabular}

Post hoc comparisons by Newman-Keuls test (six pairwise comparisons of four subtypes; required $p<.008$ ):

${ }^{a}$ Anxious pessimism: Depressive $>$ all others, $p<10^{-5}$; Psychotic $<$ all others, $p<10^{-3}$.

${ }^{b}$ Hyperactivity: Irritable $<$ all others, $p<10^{-4}$.

'Distressed appearance: Irritable $>$ all others, $p<10^{-5}$; Depressive $>$ Psychotic or Classic, $p<10^{-3}$.

${ }^{\mathrm{d}}$ Hostility: Irritable $>$ psychotic or classic, $p<.002$.

eDelusions: Psychotic $>$ all others, $p<10^{-4}$; classic $<$ all others, $p<10^{-4}$.

scores, and their treatment-related changes, more clinically relevant. Table 1 shows the items associated with each factor. Cluster analysis of the subjects based on a factor analysis of the pretreatment SADS-C and ADRS items was described by Swann et al. (2001).

\section{RESULTS}

\section{Pretreatment Characteristics of Mania Subtypes}

Principal components analysis of pretreatment rating scale data yielded six factors, characterized as impulsivity, hyperactivity, anxious pessimism, distressed appearance, hostility, and delusions (Swann et al. 2001) (Table 1). Cluster analysis of subjects based on the six factors yielded four mania subtypes. The converted factor scores for the four subtypes are shown in Table 2. There were two 'mixed' subtypes, depressive and irritable. The depressive subtype had higher anxious pessimism scores than the other groups and higher distressed appearance scores than the psychotic or classic subtypes. The psychotic subtype had the highest delusion scores, but the lowest anxious pessimism scores.
The irritable subtype had lower hyperactivity scores than all other subtypes, higher scores for hostility than psychotic or classic groups, and higher distressed appearance scores than all other groups. The largest subtype consisted of 'classic' or euphoric mania.

\section{Treatment Effects on Factor Scores}

Impulsivity and hyperactivity improved significantly more in patients randomized to either divalproex or lithium than to placebo, as shown in Table 3. Hostility improved significantly more in divalproex than in placebo-treated patients. Change in anxious pessimism, distressed appearance, or delusions did not differ among treatments.

To determine effects of the three treatments in patients whose mania improved with treatment, we conducted an analysis similar to that in Table 3 but limited to patients whose SADS manic syndrome scores improved by at least $50 \%$. Patients meeting this criterion included 9 of $69(12.9 \%)$ receiving placebo, 23 of 64 $(36 \%)$ divalproex, and 11 of $34(32.3 \%)$ lithium. Figure 1 shows their distribution across treatments and sub-

Table 3. Effects of Treatment on Factor Scores

\begin{tabular}{lcccc}
\hline & $\begin{array}{c}\text { Placebo } \\
\mathbf{( 6 6 )}\end{array}$ & $\begin{array}{c}\text { Divalproex } \\
\mathbf{( 6 1 )}\end{array}$ & $\begin{array}{c}\text { Lithium } \\
\mathbf{( 2 8 )}\end{array}$ & $\begin{array}{c}\mathbf{F} \\
\mathbf{( 2 , 1 5 2 )}\end{array}$ \\
\hline Impulsivity & $-0.08 \pm 1.24$ & $-0.69 \pm 1.13^{*}$ & $-0.70 \pm 1.37^{*}$ & $5.93(0.003)$ \\
Anxious pessimism & $0.03 \pm 0.86$ & $-0.05 \pm 1.07$ & $-0.02 \pm 0.78$ & 0.18 \\
Hyperactivity & $-0.39 \pm 1.16$ & $-0.94 \pm 1.13^{*}$ & $-1.01 \pm 1.46^{*}$ & $5.77(0.004)$ \\
Distressed Appearance & $0.15 \pm 0.87$ & $0.03 \pm 0.90$ & $0.06 \pm 1.06$ & 0.40 \\
Hostility & $0.13 \pm 1.32$ & $-0.31 \pm 1.16^{*}$ & $-0.22 \pm 0.98$ & $3.40(0.04)$ \\
Delusions & $-0.05 \pm 1.14$ & $-0.24 \pm 1.22$ & $-0.27 \pm 1.27$ & 0.84 \\
\hline
\end{tabular}

Baseline factor scores did not differ across treatment groups. Factor change scores are given with standard deviations. Comparisons used analysis of covariance with baseline score as covariate.

${ }^{*}$ Different from placebo, Newman-Keuls test, $p<.05$. 


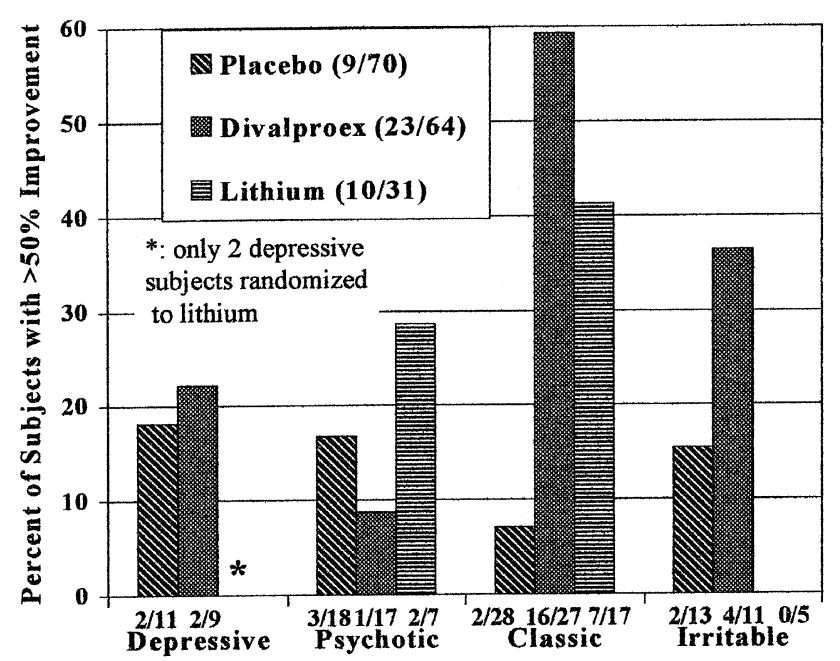

Figure 1. Percentages of subjects with over 50\% improvement in Manic Syndrome Score. The figure shows the percentage of subjects within each subtype whose Manic Syndrome Score improved more than $50 \%$ with each treatment. The legend shows the overall $50 \%$ response rate for each treatment. The number of subjects with $50 \%$ improvement and total number is shown under each bar. Note that only two patients in the Depressive subtype were randomized to lithium, and that no subjects in the irritable subtype who were randomized to lithium experienced more than $50 \%$ improvement.

types. Factor score changes in these subjects were nearly identical, regardless of treatment.

\section{Differential Treatment Response across Mania Subtypes}

Table 4 summarizes treatment effects on manic syndrome scores for the four subtypes. Patients in the classic subtype improved more with divalproex or with lithium than with placebo. Patients in the irritable subtype responded significantly better to divalproex than to lithium or placebo. There were significant improvements during treatment with divalproex in the psychotic (paired $\mathrm{t}(16 \mathrm{df})=3.2, p=.003)$, classic $(\mathrm{t}(26 \mathrm{df})=$ $5.3, p<.0001)$, and irritable $(\mathrm{t}(10 \mathrm{df})=2.7, p=.01) \mathrm{sub}-$ types and with lithium in the psychotic $(\mathrm{t}(6 \mathrm{df})=3.3, p=$ $.008)$ and classic $(\mathrm{t}(16 \mathrm{df})=3.3, p=.002)$ subtypes. The apparent deterioration with lithium treatment in the irritable subtype was not significant. There were no significant changes in mean manic syndrome scores for subjects randomized to placebo in any subgroup.

The response to lithium was significantly worse in the irritable than in the classic subtype (NewmanKeuls, $p<.05)$. There were no other significant differential subtype responses for any treatment.

Lithium and divalproex were associated with larger changes in impulsivity and hostility than placebo, re- gardless of subtype; drug-subtype interactions were nonsignificant (impulsivity $(\mathrm{F}(6,142)=0.8)$; hostility $(\mathrm{F}(6,143)=1.6)$. There was a significant drug $\mathrm{X}$ subtype interaction for change in hyperactivity $(\mathrm{F}(6,142)=2.5, p=$ $.03)$, with both lithium and divalproex differing significantly from placebo in the classic group (NewmanKeuls, $p=.03$ and 0.02 , respectively). There were no significant treatment or subtype effects on anxious pessimism or distressed appearance.

\section{DISCUSSION}

These results from a large randomized, double-blind study showed that there are naturally occurring types of manic episode that differ in response to treatment. Among the four subtypes of manic patients identified by cluster analysis, the classic subtype responded equally to divalproex and lithium, while the irritable subtype responded better to divalproex. In terms of the original hypotheses: (1) lithium and divalproex were similarly effective for hyperactivity; divalproex was not more effective than lithium for hostility across all subjects but was significantly more effective for core manic symptoms in the irritable subtype of mania; (2) lithium and divalproex were similarly effective in classic mania; lithium was less effective than divalproex in the irritable subtype; and the three treatments did not differ in efficacy for the depressive and psychotic subtypes; and (3) responders to all three treatments had similar factor changes.

These data suggest that initial treatment of the subtypes should differ. Subjects in the classic subtype could benefit from monotherapy with either lithium or divalproex, and in the irritable subtype from divalproex. Subjects in the depressive or psychotic subtypes are less likely to benefit from monotherapy and perhaps should receive combination treatments, possibly including other agents such as atypical antipsychotics (Kupka et al. 2001), from the outset.

The pattern of symptom change associated with antimanic response did not differ in patients who responded to placebo, divalproex, or lithium, suggesting that the aspects of behavior measured in manic rating scales used were nonspecific relative to the mechanisms of action of antimanic treatments, placebo, or spontaneous remission (Grof and Grof 1990; Johnstone 1988; Schaff et al. 1993). Alternatively, the endpoint time of measuring symptom change could have missed earlier indications of more specifically drug-linked behavior changes. The three treatments may have identical effects on some neurobehavioral mechanism underlying the outward manifestations of manic states (Carroll 1983). More likely, given their pharmacologic differences and differential predictors of response (Swann et al.), the treatments may alter different aspects of brain 
Table 4. Change in SADS Manic Syndrome Score for Mania Subtypes

\begin{tabular}{ccccc}
\hline & Depressive & Psychotic & Classic & Irritable \\
\hline Placebo & $-0.13 \pm 0.37$ & $-0.16 \pm 0.35$ & $-0.01 \pm 0.27$ & $-0.06 \pm 0.44$ \\
$(\mathrm{~N})$ & $(11)$ & $(18)$ & $(27)$ & $(13)$ \\
Divalproex & $-0.15 \pm 0.29$ & $-0.21 \pm 0.27^{*}$ & $-0.38 \pm 0.37^{*}$ & $-0.33 \pm 0.41^{*}$ \\
$(\mathrm{~N})$ & $(9)$ & $(17)$ & $(27)$ & $(11)$ \\
Lithium & $-0.35 \pm 0.50$ & $-0.37 \pm 0.30^{*}$ & $-0.30 \pm 0.38^{*}$ & $+0.25 \pm 0.58$ \\
$(\mathrm{~N})$ & $(2)$ & $(7)$ & $(17)$ & $(5)$ \\
Post hoc & None & None & D v P 0.001 & D v P 0.04 \\
& & & L v P 0.006 & D v L 0.004 \\
\hline
\end{tabular}

The Table shows mean changes in the Manic Syndrome Score of the SADS-C as a fraction of the pretreatment score, with standard deviations. The distribution of treatments did not vary significantly across subtypes $\left(\mathrm{X}^{2}(6 \mathrm{df})=2.8, p=0.83\right)$.

${ }^{*}$ Change different from zero, $\mathrm{P}<0.05$ (see text)

Analysis of variance: Treatment $\mathrm{F}(2,152)=3.4, \mathrm{P}=0.03$

Subtype $\mathrm{F}(3,152)=1.9, \mathrm{P}=0.14$

Treatment $x$ subtype $\mathrm{F}(6,152)=2.5, \mathrm{P}=0.02$

Post hoc comparisons used the Newman-Keuls test.

function leading to similar ultimate effects on the aspects of behavior measured by rating scales.

Antimanic responses differed across subtypes. Previous factor and cluster analyses, like ours, suggested distinct depressive subtypes of manic episodes, but did not present data on treatment response in these subtypes (Cassidy et al. 1998). Classic and irritable subtypes had clearly different responses to randomized treatments, and both responded better to at least one active treatment than to placebo. In the depressive subtype, by contrast, no treatment was associated with significant improvement. This cluster, which resembled Kraepelinian "depressive-anxious" mania, had only two subjects who were randomized to lithium, so response to lithium cannot be evaluated in it. Poor response to monotherapy was, however, consistent with the report by Dilsaver et al. that patients with combined full depressive and manic syndromes were more likely than others to require multiple treatments (Dilsaver et al. 1993).

The criterion of $50 \%$ change in Manic Syndrome Score, used in Figure 1, was stringent compared with usual standards. The overall placebo response was 13\%; within the classic subtype, placebo response was $7 \%$ while response was $59 \%$ to divalproex and $41 \%$ to lithium. By contrast, placebo response rates in recently published studies using 50\% change in the Young Mania Rating Scale were 25\% (Tohen et al. 1999) and 43\% (Tohen et al. 2000). These results underscore the roles of the specific outcome measure and population in the variations of symptom change across interventions.

The psychotic subtype had significant improvement with lithium or with divalproex, but these effects did not differ from those of placebo (Table 4). Among subjects with at least $50 \%$ improvement in mania rating scale, delusion factor scores improved significantly (mean change $-1.14 \pm 1.21, \mathrm{n}=35$, repeated measures
$\left.\mathrm{F}(1,32 \mathrm{df})=30.7, p=4 \times 10^{-6}\right)$ regardless of treatment (interaction $\mathrm{F}(2,32 \mathrm{df})=0.48, p=\mathrm{ns})$. Psychosis may therefore be a nonspecific manifestation of severe mania that improves if the underlying mania improves, possibly requiring combination treatments. There are recent reports from controlled studies that olanzapine (Tohen et al. 1999, 2000) or risperidone (Segal et al. 1998) are effective in manic episodes regardless of the presence of psychotic or mixed features, and that they may enhance response when added to lithium or divalproex (Kupka et al. 2001; Ghaemi 2000).

Fewer subjects were randomized to receive lithium, so power for comparisons involving lithium was limited. Nevertheless, there were significant antimanic responses to lithium in members of the psychotic and classic subtypes and a significant difference between lithium and divalproex for the irritable subtype (Table 4).

The impulsivity factor is the most consistent factor across subtypes (Swann et al. 2001) and the most sensitive in distinguishing effects of lithium or divalproex from placebo (Table 3). This factor is derived entirely from nurse-rated items (Table 1). Nurse ratings are rarely used in studies of treatment outcome in mania. We have previously reported ward observation to be more sensitive than interview ratings in detecting characteristics of mixed and pure manic episodes (Swann et al. 1993). Ratings based on semistructured interviews may be relied upon too heavily in mania treatment studies. Investigators should consider increased use of nurse ratings or other ratings based on direct observation of ward behavior over time.

In summary, while clinical state differentially predicts response to lithium or to divalproex, the pattern of symptom change is similar during successful treatment with lithium, divalproex, or placebo. There appear to be naturalistic subdivisions of mania that have different responses to treatment. If confirmed in other 
samples, such information could be used to guide treatment selection and refine subtypes defined in the DSM. In addition, both the behavioral factors and the manic subtypes could be investigated in relationship to biological systems implicated in bipolar disorder and pharmacodynamic mechanisms underlying response to lithium, divalproex, and other antimanic treatments.

\section{ACKNOWLEDGMENTS}

This work was supported in part by a grant from Abbott Laboratories and in part by the Pat R. Rutherford Chair in Psychiatry, University of Texas Health Science Center, Houston. We gratefully acknowledge the skilled care provided by our nursing staffs. Participants in the multicenter trial included A. Brugger, M.D., D. Morris, Ph.D., Abbott Laboratories; A. Swann, M.D., S. Dilsaver, M.D., University of Texas Health Science Center at Houston; C. Bowden, M.D., E. Garza-Trevino, M.D., University of Texas Health Science Center at San Antonio; F. Petty, M.D., Ph.D., University of Texas Southwestern Medical School at Dallas; J. Calabrese, M.D., Case Western Reserve Medical School; S.C. Risch, M.D., Medical University of South Carolina; J. Small, M.D., University of Indiana Medical School; P. Goodnick, M.D., University of Miami Medical School; J. Davis, M.D., P. Janicak, M.D., Illinois State Psychiatric Institute.

\section{REFERENCES}

Bowden CL, Brugger AM, Swann AC, Calabrese JR, Janicak PG, Petty F, Dilsaver SC, Davis JM, Rush AJ, Small JG, Garza-Trevino ES, Risch SC, Goodnick PJ, Morris DD (1994): Efficacy of divalproex vs lithium and placebo in the treatment of mania. JAMA 271:918-924

Carroll BJ (1983): Neurobiologic dimensions in depression and mania. In Angst J (ed), The Origins of Depression. Berlin, Springer-Verlag, pp 163-186.

Cassidy F, Forest F, Murry E, Carroll BJ (1998): A factor analysis of the signs and symptoms of mania. Arch Gen Psychiatry 55:27-32

Dilsaver SC, Swann AC, Shoaib AM, Bowers TC, Halle MT (1993): Mixed mania associated with non-response to antimanic agents. Am J Psychiatry 150:1548-1551

First MB, Spitzer RL, Gibbon M, Williams JB (1996): Structured Clinical Interview for DSM-IV Axis I Disorders, Patient Edition . New York: Biometrics Research Institute, New York State Psychiatric Institute.

Ghaemi SN (2000): New treatments for bipolar disorder: the role of atypical neuroleptic agents. J Clin Psychiatry 61(suppl 14):33-42

Grof P, Grof E (1990): Varieties of lithium benefit. Prog Neuropsychopharmacol Biol Psychiatry 14:689-696

Johnstone EC (1988): The Northwick Park "functional" psychosis study: Diagnosis and treatment response. Lancet ii:119-125

Kupka RW, Nolen WA, Altshuler LL, Denicoff KD, Frye MA, Leverich GS, Keck PE, McElroy SL, Rush AJ,
Suppes T, Post RM (2001): The Stanley Foundation Bipolar Network. 2. Preliminary summary of demographics, course of illness, and response to novel treatments. Br J Psychiatry Suppl 41:s177-s183

Murphy DL, Pickar D, Alterman I (1982): Methods for the quantitative assessment of depressive and manic behavior. In Burdoch EI, Sudilovsky A, Gershon S (eds), Quantitative Techniques for the Evaluation of the Behavior of Psychiatric Patients. New York, Marcel Dekker, pp 355-393.

Schaff MR, Fawcett J, Zajecka JM (1993): Divalproex sodium in the treatment of refractory affective disorders. J Clin Psychiatry 54:380-384

Segal J, Berk M, Brook S (1998): Risperidone compared with both lithium and haloperidol in mania: a double-blind randomized controlled trial. Clin Neuropharmacol 21:176-180

Spitzer RL, Endicott J (1978a): Schedule for Affective Disorders and Schizophrenia, 3rd ed. New York, New York State Psychiatric Institute Biometrics Inst.

Spitzer RL, Endicott J (1978b): Schedule for Affective Disorders and Schizophrenia: Change Version, 3 ed. New York, Biometrics Research, New York State Psychiatric Institute.

Spitzer RL, Endicott J, Robins E (1978): Research Diagnostic Criteria for a Selected Group of Functional Disorders, 3 ed. New York, New York State Psychiatric Institute Biometrics Inst.

Swann AC, Bowden CL, Morris D, Calabrese JR, Petty F, Small JG, Dilsaver SC, Davis JM (1997): Depression during mania: Treatment response to lithium or divalproex. Arch Gen Psychiatry 54:37-42

Swann AC, Bowden CL, Calabrese JR, Dilsaver SC, Morris DD (1999): Differential effect of number of previous episodes of affective disorder on response to lithium or divalproex in acute mania. Am J Psychiatry 156:12641266.

Swann AC, Janicak PG, Calabrese JR, Bowden CL, Dilsaver SC, Morris DD, Petty F, Davis JM (2001): Structure of mania: Depressive, irritable, and psychotic clusters with distinct courses of illness in randomized clinical trial participants. J Affective Disord (in press)

Swann AC, Secunda SK, Katz MM, Croughan J, Bowden CL, Koslow SH, Berman N, Stokes PE (1993): Specificity of mixed affective states: Clinical comparison of mixed mania and agitated depression. J Affective Disord 28: 81-89

Swann AC, Secunda SK, Katz MM, Koslow SH, Maas JW, Chang S, Robins E (1986): Lithium treatment of mania: Clinical characteristics, specificity of symptom change, and outcome. Psychiatry Res 18:127-141

Swann AC, Stokes PE, Casper R, Secunda SK, Bowden CL, Berman N, Katz MM, Robins E (1992): Hypothalamicpituitary-adrenocortical function in mixed and pure mania. Acta Psychiatr Scand 85:270-274

Tohen M, Jacobs TG, Grundy SL, McElroy SL, Banov MC, Janicak PG, Sanger T, Risser R, Zhang F, Toma V, Francis J, Tollefson GD, Breier A (2000): Efficacy of olanzapine in acute bipolar mania: a double-blind, placebocontrolled study. The olanzapine HGGW Study Group. Arch Gen Psychiatry 57:841-849 
Tohen M, Sanger TM, McElroy SL, Tollefson GD, Chengappa KN, Daniel DG, Petty F, Centorrino F, Wang R, Grundy SL, Greaney MG, Jacobs TG, David SR, Toma V (1999): Olanzapine versus placebo in the treatment of acute mania. Olanzapine HGEH Study Group. Am J Psychiatry 156:702-709
Tohen M, Waternaux CM, Tsuang MT (1990): Outcome in mania. A 4-year prospective follow-up of 75 patients utilizing survival analysis. Arch Gen Psychiatry 47: 1106-1111

Winer BJ (1971): Statistical Principles in Experimental Design, 2nd ed. New York, McGraw-Hill 